\title{
Palliation of symptoms in non-small cell lung cancer: a study by the Yorkshire Regional Cancer Organisation thoracic group
}

\author{
M F Muers, C E Round on behalf of the group
}

\begin{abstract}
Background-Although most treatment for non-small cell lung cancer is palliative, data on the adequacy of symptom control are scanty and there has been little discussion about the appropriate indices.

Methods-Two hundred and eighty nine unselected patients presenting sequentially to six specialists were studied; 242 cases were confirmed histologically and all were managed as non-small cell lung cancer. At presentation and two monthly for one year or until death each of 12 symptoms was graded by a physician at a clinic interview on a four point scale as absent, mild, moderate, or severe. For each symptom a palliative index (median duration of control/median duration of survival) was calculated, where control was defined as an improvement in symptoms of any severity by one grade or more.

Results-Sixty four (22\%) patients had surgery, 15 (5\%) radical and $107(37 \%)$ palliative radiotherapy, and $103(36 \%)$ best supportive care. Analysis showed that most symptoms inexorably worsened with time. The palliation index for haemoptysis was $86 \%$, chest pain $73 \%$, cough $34 \%$, and breathlessness $30 \%$; for systemic symptoms it was $54 \%$ for anorexia and $47 \%$ for malaise. Palliation was poor in many patients after surgery. Breathlessness was a particular problem in the group having best supportive care. Conclusions-The frequency of most symptoms in non-small cell lung cancer increases inexorably with time until malaise and anorexia are almost universal. Haemoptysis and chest pain are better palliated than cough and breathlessness. Present treatments fail to give adequate palliation for many patients, and the emphasis in future therapeutic studies should be on the relief of the more severe symptoms.
\end{abstract}

(Thorax 1993;48:339-343)

About 35000 new cases of lung cancer occur each year in the United Kingdom. Most of these are non-small cell lung cancer. Apart from the $20 \%$ who are offered surgery and the very few who have radical radiotherapy ${ }^{1}$ there is no evidence that most patients have their prognosis appreciably altered by medical treatment or that their prognosis has improved over the last 10 years. ${ }^{23}$ Consequently the role of non-surgical management in non-small cell lung cancer is to palliate symptoms. Apart from studies on radiotherapy regimens ${ }^{45}$ and a little work on terminal care, ${ }^{67}$ however, there have been no detailed assessments of the efficacy of symptom relief or of the pattern and development of symptoms after presentation. It is important to acquire such data because any consequent changes in the management of non-small cell lung cancer will have major practical and economic consequences. ${ }^{8}$

As part of a multicentre prospective study in the management of non-small cell lung cancer in our region, we have examined the pattern of symptoms and palliation in nearly 300 unselected patients presenting to four physicians and two radiotherapists.

\section{Methods}

PATIENTS AND CLINICAL DATA

Patients were recruited sequentially from the clinics of four chest physicians (CKC, MFM, MDP, SBP) and two radiotherapists (DA and HJC). Any patient being managed on the basis of a diagnosis of non-small cell lung cancer was entered and no selection criteria within this category were applied. Patients were asked at the consultation at which management was decided to grade each of 12 symptoms relevant to lung cancer on a four point scale (severe, moderate, mild, or absent). Activity was assessed on a World Health Organisation (WHO) scale. ${ }^{9}$ Assessments were repeated in the same way at two month intervals for one year or until death. Interviewers were hospital doctors of registrar grade or above. The study was approved by the clinical research ethics committees of the participating physicians' health districts. All data were entered on structured forms and analysed on a Bull PC with the statistical package SAS.

At the end of the study the presenting features and the clinical course of all patients without histological confirmation were reviewed. Patients were finally accepted as having non-small cell lung cancer without histological confirmation only if (1) they had no evidence of any other disease to explain their clinical presentation and course;

Returned to authors

4 June 1992 .

14 September 1992

Accepted 10 November 1992 
they had an abnormality on their chest radiograph at presentation that worsened during the period of observation; (3) they had a clinical course during observation that was compatible with progressive carcinoma or they died during the period of observation with evidence of an enlarging tumour or metastatic disease; (4) they did not have a serum neurone specific enolase value greater than 12 $\mathrm{U} / \mathrm{ml}$; (5) they had no evidence of a primary tumour elsewhere. The clinical course of these patients was indistinguishable from that of patients with histological confirmation.

\section{STATISTICAL METHODS}

\section{Trends in symptoms with time}

As symptoms at presentation represent a cross section of times during the natural history of the disease, trends in the proportion of patients having a particular symptom, regardless of its severity, were related to death rather than presentation. Thus cohorts were identified according to how many months before death a patient presented. The trends were described for each of these cohorts to confirm that the changes were similar throughout; the data were then combined and the resulting trend was assumed to be representative of the experience of all patients irrespective of the time of presentation and therefore to be a true reflection of the actual changes.

\section{Palliation of symptoms}

The degree of palliation of symptoms was expressed in terms of a percentage palliation index:

$$
\frac{\text { median duration of control of a symptom }}{\text { median duration of follow up period }} \times 100 \text {. }
$$

The duration of symptom control was defined as the period of time after onset during which a symptom's severity was reduced. The symptom follow up period was taken to extend from the point of the symptom's first occurrence either to death or to the end of the study. This method of measuring the palliation of symptoms was chosen as it took into account the variable duration of survival.

The improvement between different points on a symptom scale cannot be assumed to have the same impact and so the palliation index (PI) was calculated in two ways:

Table 1 Numbers (and percentages) of the 289 patients with non-small cell lung cancer reporting particular symptoms at presentation

\begin{tabular}{lcccc}
\hline \multicolumn{4}{l}{ No (\%) of patients } & \\
\cline { 2 - 5 } Symptoms & All grades & Severe & Moderate & Mild \\
\hline Cough & $228(79)$ & $12(4)$ & $101(35)$ & $116(40)$ \\
Haemoptysis & $101(35)$ & $4(1)$ & $30(10)$ & $67(23)$ \\
Breathlessness & $216(75)$ & $23(8)$ & $95(33)$ & $98(34)$ \\
Chest pain & $107(37)$ & $9(3)$ & $40(14)$ & $58(20)$ \\
Other pain & $37(13)$ & $6(2)$ & $14(5)$ & $17(6)$ \\
Hoarseness & $32(11)$ & $6(2)$ & $6(2)$ & $20(7)$ \\
Anorexia & $130(45)$ & $10(3)$ & $47(16)$ & $73(25)$ \\
Malaise & $136(47)$ & $6(2)$ & $43(15)$ & $87(30)$ \\
Dysphagia & $20(7)$ & 0 & $6(2)$ & $14(5)$ \\
Abdominal pain & $15(5)$ & 0 & $9(3)$ & $6(2)$ \\
Headache & $22(8)$ & 0 & $4(1)$ & $18(6)$ \\
Others & $49(17)$ & $4(1)$ & $38(13)$ & $7(2)$ \\
\hline
\end{tabular}

PI[1]: when all grades at presentation (severe, moderate, mild) improved by one grade or more;

PI[2]: when severe or moderate symptoms were improved at least to mild and initially mild symptoms improved by one grade or remained unchanged.

Patients for whom the symptom was recorded as absent throughout were excluded. The palliation index for performance status was expanded from PI[1] to include the maintenance of grade 0 .

\section{Results}

\section{PATIENTS}

The original population consisted of 330 patients. Two hundred and forty two had tumours histologically confirmed as nonsmall cell lung cancer. Review of the 88 patients without histological confirmation showed that 11 had small cell lung cancer and 23 had non-cancerous lesions; data were insufficient in seven cases. The remaining 47 fulfilled the criteria given above in support of a diagnosis of primary non-small cell lung cancer and were included in the analysis. Thus the final population consisted of 289 patients (232 men), mean age 66 (SD 9.64) years. The distribution between centres was: physician 1-92 patients; physician 2-83; physician 3-47; physician 4-17; radiotherapist $1-35$; radiotherapist $2-12$.

Data on patients at presentation were complete. The numbers of patients potentially providing data at the subsequent follow up visits were: 2 months-260 (90\%), 4 months-234 (81\%), 6 months-214 (74\%), and 12 months-165 (57\%).

\section{MANAGEMENT AND SURVIVAL}

The initial management of these 289 patients was surgery in 64 patients (22\%), radical radiotherapy in $15(5 \%)$, immediate palliative radiotherapy in $107(37 \%)$, and best supportive care in $103(36 \%)$. The patients having best supportive care had no immediate anticancer treatment and only 12 had later palliative radiotherapy. Their mean age was 70 years and the distribution of their initial performance status ratings was not different from that of the group as a whole. The proportions of the group having best supportive care and of the whole group falling into the different WHO grades were: Grade $0-23 \%$ and $87 / 289(30 \%)$; grade $1-37 \%$ and $36 \%$; grade $2-29 \%$ and $28 \%$; grade $3-8 \%$ and $5 \%$; grade $4-3 \%$ and $2 \%$.

The patients' survival at 12 months according to their initial management was: surgery $33 / 64(52 \%)$, radical radiotherapy $7 / 15(47 \%)$, palliative radiotherapy $22 / 107$ (21\%), best supportive care $20 / 103$ (19\%). The median survival was 6 (interquartile range 3-14) months overall, 6 (3-11) months after palliative radiotherapy, and 4 (1-8) months with best supportive care.

SYMPTOMS AT PRESENTATION (TABLE 1) As expected, the most common and severe symptoms were cough and breathlessness. 
Percentages of patients experiencing the six major symptoms of lung cancer in the 12 months before death.
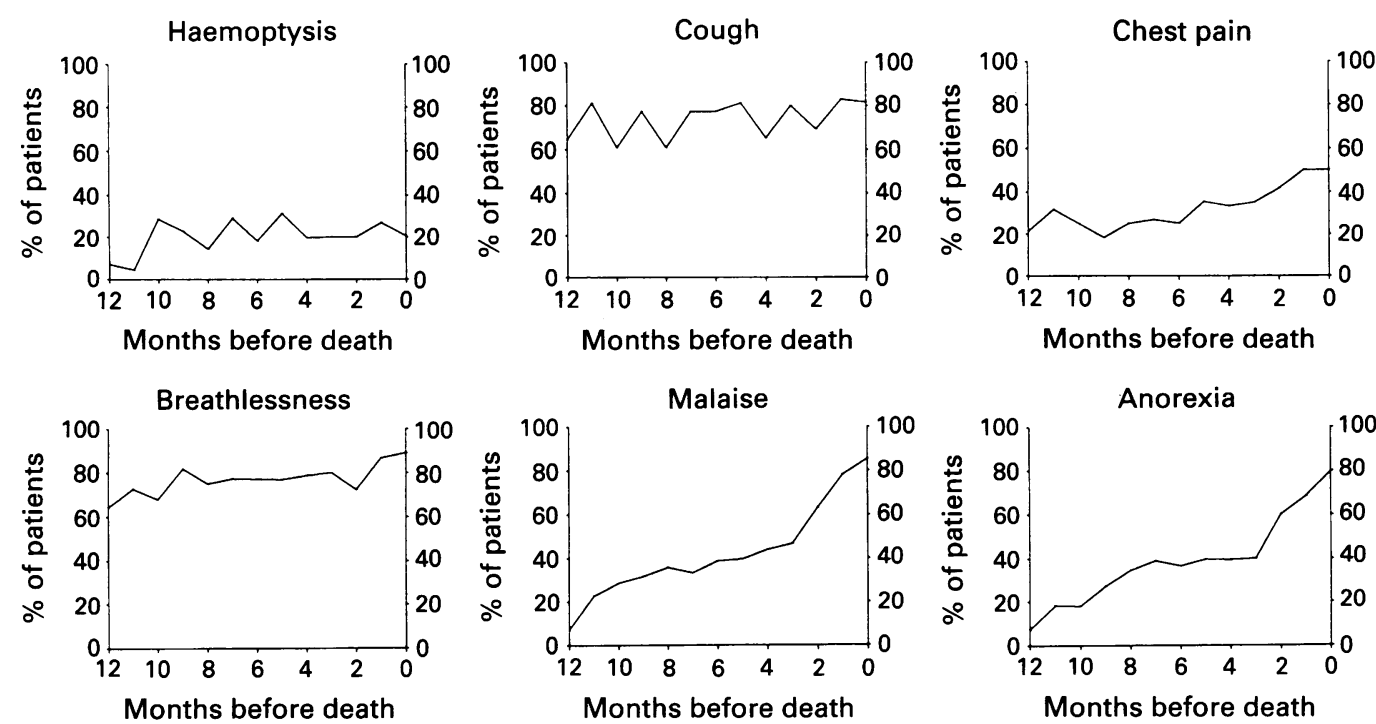

These were experienced by three quarters of patients, and were moderate or severe in about half of these. Haemoptysis and chest pain were present in just over one third but severe symptoms were rare. Other localised symptoms were much less common. One hundred and thirty $(45 \%)$ of the 289 patients presented with systemic symptoms of anorexia or malaise, which were moderate or severe in $57(19 \%)$ and $49(17 \%)$.

\section{CHANGE OF SYMPTOMS WITH TIME (FIGURE)}

As the figure shows, most symptoms eventually became more common despite efforts at palliation. Although haemoptysis and cough showed less change, chest pain, breathlessness and in particular the systemic symptoms malaise and anorexia increased inexorably. This illustrates why the last two are such powerful negative prognostic factors in the disease.

\section{PALLIATION OF SYMPTOMS (TABLE 2)}

From the whole population of 289 the number of patients experiencing any grade of each symptom and the corresponding palliation indices are shown on the left hand side of table 2. Blanks indicate where the numbers are too small for analysis. For PI[1], among the respiratory symptoms haemoptysis and

Table 2 Palliation indices* (PI, \%) for symptoms among the 289 patients with non-small cell lung cancer

\begin{tabular}{|c|c|c|c|c|c|}
\hline & \multicolumn{3}{|c|}{ All grades } & \multicolumn{2}{|c|}{ Moderate and severe } \\
\hline & $n$ & $P I[1]^{*}$ & $P I[2]^{\star}$ & $n$ & $P I[1][2]^{*}$ \\
\hline Cough & 177 & 34 & 78 & 95 & 76 \\
\hline Haemoptysis & 81 & 86 & 98 & 27 & 90 \\
\hline Breathlessness & 175 & 30 & 59 & 113 & 55 \\
\hline Chest pain & 99 & 73 & 84 & 48 & 76 \\
\hline Hoarseness & 30 & 74 & 68 & 16 & - \\
\hline Other pain & 47 & 75 & 85 & 26 & 77 \\
\hline Malaise & 114 & 47 & 72 & 38 & 42 \\
\hline Anorexia & 98 & 54 & 79 & 38 & 54 \\
\hline Dysphagia & 17 & - & - & 5 & - \\
\hline Abdominal pain & 21 & 62 & 90 & 7 & - \\
\hline Headache & 19 & - & - & 2 & - \\
\hline Others & 59 & 66 & 76 & 53 & 66 \\
\hline
\end{tabular}

^For definition see under "Methods." chest pain are relatively well palliated (over $70 \%$ ) whereas cough and breathlessness are much worse controlled (less than $35 \%$ ). There is some palliation of anorexia and malaise (over $45 \%$ ) and moderately good control of abdominal pain and hoarseness.

If we allow that the persistence of mild symptoms indicates some palliation, in the face of generally increasing frequency (figure), then PI[2] is a more appropriate index than PI[1]. Its use keeps the relative success of management in palliating different symptoms constant but changes some absolute values considerably. For example, the palliation of cough increases from $34 \%$ to $78 \%$ and breathlessness from $30 \%$ to $59 \%$.

If we consider only moderate or severe symptoms (table 2 right hand columns) then PI[1] and PI[2] are the same. Comparisons across the whole table show that PI[2] for all grades generally corresponds better than PI[1] to the effect of management on moderate or severe respiratory symptoms. In particular, it is dominated less than PI[1] by the persistence of mild symptoms of cough and breathlessness. For systemic symptoms, on the other hand, PI[1] is better as fewer patients with anorexia or malaise improved.

\section{ACTIVITY SCORE ANALYSIS}

Palliation indices, which are medians, were zero for activity score. Nevertheless, 40 patients $(20 \%)$ showed an improvement for part of the follow up period, ranging from 56 to 330 days, and the proportion of control in these patients ranged from $15 \%$ to $90 \%$. Thirty eight $(19 \%)$ reported an improvement throughout the entire period of follow up.

\section{PALLIATION AND INITIAL TREATMENT} MODALITY (TABLE 3)

Table 3 shows symptom palliation in each initial treatment group on the basis of PI[2] for all grades (left hand columns). PI[1] and PI[2] are the same where moderate or severe symptoms only are considered (right hand columns). 
Table 3 Numbers (and percentages) of palliation indices* (PI) by initial treatment among the 289 patients with non-small cell lung cancer

\begin{tabular}{|c|c|c|c|c|c|c|}
\hline \multirow[b]{2}{*}{ Symptom } & \multicolumn{3}{|c|}{$A l l$ grades $\left(P I[2]^{\star}\right)$} & \multicolumn{3}{|c|}{ Moderate and severe $\left(P I[1][2]^{\star}\right)$} \\
\hline & $S$ & $R T(P)$ & $B S C$ & $S$ & $R T(P)$ & $B S C$ \\
\hline $\begin{array}{l}\text { Cough } \\
\text { Haemoptysis } \\
\text { Breathlessness } \\
\text { Chest pain }\end{array}$ & $\begin{array}{l}42(69) \\
22(100) \\
44(75) \\
29(63)\end{array}$ & $\begin{array}{l}66(72) \\
29(98) \\
66(61) \\
32(82)\end{array}$ & $\begin{array}{l}57(95) \\
26(100) \\
52(37) \\
26(83)\end{array}$ & $\begin{array}{l}25(62) \\
9 \dagger \\
23(74) \\
10 \dagger\end{array}$ & $\begin{array}{l}39(46) \\
11 \dagger \\
52(53) \\
22(72)\end{array}$ & $\begin{array}{l}25(93) \\
6 \dagger \\
30(28) \\
15 \dagger\end{array}$ \\
\hline
\end{tabular}

S-surgery; RT(P)—palliative radiotherapy; BSC—best supportive care.

^For definition see under "Methods."

†Numbers too small for analysis. patients did represent what they were really experiencing.

\section{COMPARISON WITH PREVIOUS STUDIES}

Previous studies measuring palliation in nonsmall cell lung cancer have considered only patients referred particularly for radiotherapy ${ }^{415}$ or surgery. ${ }^{1617}$ Primary chemotherapy is rarely used in the United Kingdom for non-small cell lung cancer, and no studies have focused particularly on palliation after it. Our study population included patients treated by radiotherapy and surgery and also the third of patients who were treated by physicians and not referred. This group has not previously been studied.

Nou et $a l^{16}$ showed that patients undergoing surgery and subsequently relapsing have substantial symptoms and our study reinforces this. Over $40 \%$ of our surgically treated patients died within the first year and the palliation indices in this group were not better than in the other groups (table 3 ).

The format of our study allows a comparison of symptom palliation in our patients and in those of the recent radiotherapy dosage study by the MRC working party, which used a similar index. ${ }^{5}$ If mild, moderate and severe breathlessness on our scale are equated with 3-5 on the MRC scale the comparisons are as follows:

For the PI[1] in our study: cough $18 \%$, haemoptysis $98 \%$, breathlessness $41 \%$, chest pain $72 \%$; for the MRC study: cough $50 \%$, haemoptysis $80 \%$, breathlessness $50 \%$ and chest pain $57 \%$.

Comparison with the few other studies is more difficult. Slawson and Scott ${ }^{15}$ reported a study of radiotherapy, usually $60 \mathrm{~Gy}$ over six weeks (currently regarded in Britain as radical treatment), or less in iller patients. In their patients with non-small cell lung cancer undefined "responses" were: haemoptysis $77 / 90$ (86\%), breathlessness $34 / 59$ (58\%), and chest pain $40 / 69(58 \%)$. More recently Collins et $a l^{4}$ studied 96 patients treated with palliative radiotherapy and assessed three and six months later as improved, the same, or worse by comparison with their presenting symptoms. The percentages of patients alive and reporting improvement in symptoms after thes: two intervals were: cough $68 \%$ and $27 \%$, haemoptysis $88 \%$ and $63 \%$, breathlessness $53 \%$ and $32 \%$, and chest pain $72 \%$ and $33 \%$. Eleven out of 94 patients $(12 \%)$ died before their first follow up. The results of both of these studies confirm that, unlike haemoptysis, the other major symptoms of lung cancer, especially breathlessness, are not well palliated by radiotherapy.

\section{SEVERTTY OF SYMPTOMS AND THEIR IMPACT}

The MRC study 5 gave equal weight to the relief of a mild symptom (which becomes absent) and the improvement from severe to absent. There are reasons for believing that a more appropriate index in the setting of nonsmall cell lung cancer may be to regard palliation as adequate if severe or moderate symptoms are reduced to mild or absent and diary card system that we know of This showed a good concordance between the two methods and supports the contention that the symptom gradings reported by our 
mild symptoms remain and do not worsen (PI[2]). This is because nearly all patients with non-small cell lung cancer are current smokers or ex-smokers with a high background incidence of cough, sputum, breathlessness, and variable chest tightness due to diffuse airway disease, which pre-exists and persists alongside the local effects of their tumour. The focus of palliation then becomes the patient who presents with moderate or severe symptoms and in whom the target of palliation should be to make symptoms mild or absent. This suggestion seems clinically appropriate but needs validation for nonsmall cell lung cancer by correlating the reported severity of each symptom with an assessment of its impact and the concern a patient feels about it.

\section{SYMPTOMS}

Haemoptysis is palliated whatever treatment policy for non-small cell lung cancer is adopted (table 3). Chest pain deriving from lung cancer has not been analysed in detail in any prospective study. We have shown that it persists after surgery, when it presumably relates to the thoracotomy. We believe that this symptom merits a further, more detailed analysis to establish which types of pain respond to direct antitumour treatment. Cough and breathlessness are the major respiratory symptoms of lung cancer and are less well palliated. Coexistent diffuse airway disease, however, is likely to be a component of the symptom pattern in many patients and its severity and response to therapy has not, so far as we are aware, been studied prospectively in any series.

Corticosteroids are the only widely used treatment to ameliorate the systemic symptoms of malaise and anorexia in non-small cell lung cancer. Anecdotally they seem to have a transient effect in milder cases. As the analysis of symptom pattern shows (figure), systemic symptoms are likely to dominate activity scores and quality of life assessments later in the disease in all patients.

Palliation of the less common subsidiary symptoms in non-small cell lung cancer is fairly good, to judge by palliation indices of $60 \%$ or more (table 2). The number of patients presenting with moderate or severe subsidiary symptoms (less than $7 \%$ ) is too small for comparisons between treatment modalities to be made.

We wish to thank Mrs V Saunders and her secretariat for their invaluable support and Mrs E Power for her secretarial assistance. The study was generously supported by the Yorkshire Regional Cancer Organisation.

\section{Appendix World Health Organisation classification of performance status}

\begin{tabular}{|c|c|c|}
\hline Grade & Summary & Description of performance status \\
\hline 0 & Normal & $\begin{array}{l}\text { Able to carry out all normal } \\
\text { activity without restriction }\end{array}$ \\
\hline 1 & With effort & $\begin{array}{l}\text { Restricted in physically } \\
\text { strenuous activity but ambulatory } \\
\text { and able to carry out light work }\end{array}$ \\
\hline 2 & Restricted & $\begin{array}{l}\text { Ambulatory and capable of all } \\
\text { self care but unable to carry out } \\
\text { any work; up and about more than } \\
50 \% \text { of waking hours }\end{array}$ \\
\hline 3 & Dependent & $\begin{array}{l}\text { Capable of only limited self } \\
\text { care; confined to bed or chair } \\
\text { more than } 50 \% \text { of waking hours }\end{array}$ \\
\hline 4 & Immobile & $\begin{array}{l}\text { Completely disabled; cannot carry } \\
\text { on any self care; totally } \\
\text { confined to bed or chair. }\end{array}$ \\
\hline
\end{tabular}

1 Komaki R, Cox JD, Hartz AJ, Byhardt RW, PerezTamayo C, Clowry L, et al. Characteristics of long-term survivors after treatment for inoperable carcinoma of the lung. Am $\mathcal{f}$ Clin Oncol 1985;8:362-70.

2 Durrant KR, Berry RJ, Ellis F, Ridehalgh FR, Black JM, Hamilton WS. Comparison of treatment policies in inoperable bronchial carcinoma. Lancet 1971;i:715-9.

3 Connolly CK, Jones WG, Thorogood J, Head C, Muers MF. Investigation, treatment and prognosis of bronchial carcinoma in the Yorkshire Region of England, 1976-83. Br ₹ Cancer 1990;60:579-83.

4 Collins TM, Ash DV, Close HJ, Thorogood J. An evaluation of the palliative role of radiotherapy in inoperable carcinoma of bronchus. Clin Radiol 1988;39:284-6.

5 Medical Research Council lung cancer working party. Inoperable non-small-cell lung cancer (NCLC): Medical Research Council randomised trial of palliative radiotherapy with two fractions or ten fractions. $\mathrm{Br} \mathcal{F}$ Cancer 1991;63:265-70.

6 Twycross RG. The terminal care of patients with lung cancer. Postgrad Med F 1973;49:732-7.

7 Reuben DB, Mor V. Dyspnoea in the terminally ill cancer patient. Chest 1986;89:234-6.

8 Maher EJ, Dische S, Grosch E, Fermont D, Ashford R, Saunders $\mathrm{M}$, et al. Who gets radiotherapy? Health Trends 1990;22:78-83.

9 World Health Organisation. Handbook for reporting results of cancer treatment. Geneva: WHO, 1979.

10 Maguire P, Selby P. Assessing quality of life in cancer patients. Br $\mathcal{F}$ Cancer 1989;60:437-40.

11 Ferguson RJ, Cull A. Quality of life measurement for patients undergoing treatment for lung cancer. Thorax 1991;46:671-5.

12 Kaasa S, Mastekassa A, Naess S. Quality of life of lung cancer patients in a randomised clinical trial evaluated by a psycho-social well-being questionnaire. Acta Oncol 1988;27:335-42.

13 Coates A, Dillenbeck CF, McNeil DR, Kaye SB, Sims K, Fox RM, et al. On the receiving end-II Linear analogue self-assessment (LASA) in evaluation of aspects of the quality of life of cancer patients receiving therapy. Eur f Cancer Clin Oncol 1983;19:1633-7.

14 Medical Research Council Lung Cancer Working Party. Survival, adverse reactions and quality of life during combination chemotherapy compared with selected palliative treatment for small-cell lung cancer. Respir Med liative treatmen
$1989 ; 83: 51-8$.

15 Slawson RG, Scott RM. Radiation therapy in bronchogenic carcinoma. Radiology 1979;132:175-6.

16 Nou E, Aberg T. Quality of survival in patients with surgically treated bronchial carcinoma. Thorax 1980;35: cally treat

17 Hamelmann $H$, Thermann $M$, Muller-Schwefe $T$, Schnurer C, Troidl H. Surgically treated bronchial carcinoma patients - results of systematic follow up. Thorac Cardiovasc Surg 1983;31:41-4. 